\title{
ФИНАНСОВЫЙ ИНТЕЛЛЕКТ КАК НЕОБХОДИМОЕ КАЧЕСТВО УСПЕШНОГО МЕНЕДЖЕРА В СОВРЕМЕННОЙ ЭКОНОМИКЕ
}

\author{
(C) 2020 Кочетова Маргарита Вячеславовна \\ студент \\ Самарский государственный экономический университет, Россия, Самара \\ E-mail: margo8090@mail.ru \\ (c) 2020 Полынова Людмила Викторовна \\ кандидат экономических наук, доцент \\ Самарский государственный экономический университет, Россия, Самара
}

Современный этап развития глобальной экономики, в том числе и российской, предъявляет новые требования к развитию управленческих компетенций руководителей (менеджеров). Основой их развития являются различные виды интеллекта, особое место среди них отводится эмоциональному и финансовому. В настоящее время выяснено, что человек обладает множеством различных видов интеллекта, которые были выработаны и исследованы учеными и экономистами со всего мира. Эмоциональный интеллект (EQ) изучен Дж. Майером и П. Сэловейем; финансовый интеллект (FQ) рассмотрен Робертом Кийосаки, который и стал основоположником этого вида интеллекта. В проведенном исследовании было выявлено, насколько связаны $\mathrm{EQ}$ и FQ, какие люди обладают FQ и как его можно развивать для формирования финансовой компетентности.

Ключевые слова: финансовый интеллект, Р. Кийосаки, эмоциональный интеллект, менеджер, развитие интеллекта, финансовая компетентность.

\section{Основные положения:}

- После признания тестов IQ (коэффициента интеллекта) неэффективными, все большую популярность для менеджеров набирает EQ эмоциональный интеллект, сущность которого состоит в способности к самосознанию, саморегулированию, мотивации, умении сочувствовать и общаться, то есть EQ - способность понимать свои и чужие эмоции.

- Финансовый интеллект, все более набирающий популярность среди всех специальностей и профессий, стал одним из важнейших видов интеллекта, который представлен Робертом Кийосаки в пяти видах.

- Анализ и сравнение разных видов интеллекта дает возможность понимать, как проще их развивать в совокупности. Без одного не получится реализовать другое.

- Исследование наличия у людей разных специальностей и направлений деятельности FQ дает возможность определить, с помощью каких методов его можно развивать для формирования финансовой компетентности.

\section{Введение}

Что дает возможность менеджеру или любому человеку, работающего в сфере бизнеса, быть успешным? - Конечно, знания, квалификация, образование, опыт. Таким образом он развивает свой интеллектуальный уровень, но в результате многочисленных исследований доказано, что, чтобы быть еще успешней, мало повышать выше перечисленные составляющие,- нужно обладать разнообразными видами интеллекта. Особое внимание в вопросе лидерства уделяется эмоциональному интеллекту, который позволяет человеку контролировать свои эмоции с помощью самосознания и саморегулирования, управлять эмоциями других в силу таких навыков, как сочувствие, мотивация, способности к общению. На его фоне выделяется финансовый интеллект, который также не менее важен в развитии своих управленческих навыков. Он помогает руководителю развивать умение увеличивать, сберегать, рациональнее использовать, распределять финансы и повышать свою финансовую компетентность. Осознание важности и актуальности FQ сподвигло авторов статьи исследовать его наличие у людей из разных сфер деятельности, в том числе руководителей, и возможности его развития. За основу при определении FQ и его видов была взята классификация Кийосаки (стр. 7). 


\section{Методы}

В качестве основного метода исследования авторами был использован опрос в виде анкетирования людей различных специальностей, в том числе руководителей, а также студентов экономических направлений, с целью выявления соотношения рода деятельности и владения финансовым интеллектом для последующей разработки рекомендаций по его совершенствованию и развитию финансовой компетентности. Также был проведен анализ научной литературы по исследованию эмоционального и финансового интеллектов, таких как Г. Гарднер, Р.Кийосаки, Д. Гоулман, сравнение этих видов интеллекта на основе их положений, синтез проверенных данных и выведение результатов. Для определения финансовой грамотности были заданы следующие вопросы: Есть ли у вас работа? В какой сфере вы работаете? Какова ваша должность (функции)? Задумываетесь ли вы о том, как улучшить свое финансовое положение, увеличить доходы? Умеете ли вы сберегать/откладывать деньги? Полагаетесь ли вы на мнение других людей в вопросе использования денежных средств? Планируете ли вы свой бюджет? Как часто вы планируете свой бюджет? Инвестируете ли вы деньги? Если да, то в какие сферы? Имеете ли вы вклады в банке? Имеете ли вы кредиты? Если вы имеете кредиты, то какие? Каким способом вы расплачиваетесь с кредитом? Пользуетесь ли вы банковскими картами? Если да, то какими? Как вы оцениваете уровень своей финансовой компетентности?

\section{Результаты}

В процессе анкетирования на предмет определения финансовой компетентности лиц различных профессий и лиц разного уровня власти было опрошено 50 человек, среди них: 51,6\% - мужчины,48,4\%-женщины. 80\% респондентов имеют работу в различных сферах: про- изводство (34,6\%), коммерческий бизнес, в том числе бизнес в сфере финансов, медицина (7,7\%), строительство (19,2\%), торговля, государственная служба. (см. рис.1), 20\% - не имеющие работу студенты.

На вопрос «Задумываетесь ли вы о том, как улучшить свое финансовое положение, увеличить доходы?» 72\% отвечают, что постоянно думают и реализовывают свои планы в жизнь, при этом 7\% из работающей аудитории уже реализовали их, в основном, это руководители различных компаний, их устраивает свое финансовое положение. $21 \%$ - в большинстве студенты, которые задумываются, но не претворяют свои желания в жизнь. Этот вопрос нацелен на возможность определения человеком, что можно сделать, чтобы увеличить свои финансовые активы - если он постоянно ставит четкие цели по развитию своего бизнеса и реализовывает их, то у него высокий уровень финансового интеллекта № 1 «Умение делать деньги».

При ответе на вопрос «Умеете ли вы сберегать/откладывать деньги?» 87\% уверенно говорят, что умеют, среди них наблюдаются как взрослые люди, так и студенты. Но остальная часть - студенты, которые живут с родителями, и их финансовое положение зависит от них. Это умение характеризуется финансовым интеллектом № 2 «Умение сберегать» и означает, что люди, знающие, как сберегать, обладают большим финансовым интеллектом, чем те, кто не могут и тратят деньги неразумно.

93\% планируют свой бюджет, причем 53\% делают это каждый месяц. Часть респондентов, планирующих свой бюджет несколько раз в месяц, а иногда и каждую неделю, составляют люди, работающие в сфере производства и являющимися руководителями проектов, так как их заработок часто зависит от успешности произведенного проекта, они периодически пересматривают свои расходы. Планирование бюджета
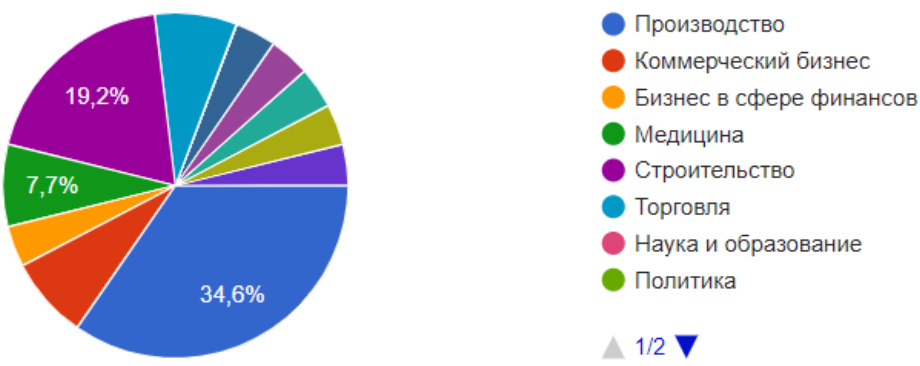

Puc. 1. «Структура респондентов по сферам деятельности» 
является неотъемлемой частью $\mathrm{FQ}$, так как человек, который умеет планировать свой бюджет, наиболее эффективно распоряжается доходами и расходами (FQNo 3 «Умение составлять бюджет»).

Совершенно разные ответы на вопрос «Полагаетесь ли вы на мнение других людей в вопросе использования денежных средств?» были вызваны следующей тенденцией: студенты, в основном не работающие, отвечают, что полагаются постоянно на своих родителей, от которых зависят финансово, а работающие студенты говорят - «Никогда», а управленцы либо иногда выслушивают мнение других, либо редко (рис. 2).

35\% инвестируют свои средства в различные сферы, в большей степени в недвижимость и ценные бумаги, также в ПИФ, нефтяную отрасль. В основном это люди, работающие в различных сферах и занимающие управляющие должности (генеральный директоры, начальники отдела). По классификации Р. Кийосаки, таким видом интеллекта, который характеризует умение пользоваться «эффектом рычага», то есть пытаться инвестировать свой капитал для увеличения собственных средств, является № 4 и говорит о том, что если человек им обладает, то он развивает свой FQ.

Также в блоке об использовании денежных средств разными способами состоит вопрос о наличии вкладов или кредитов в банке у опрошенных. 50\% имеют вклад, среди них высоко

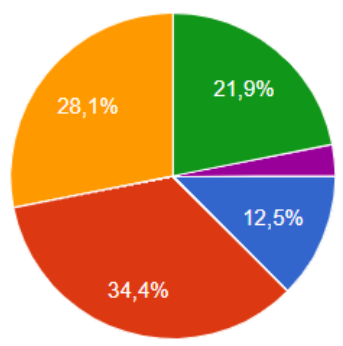

число тех, кто инвестирует куда-либо еще свои средства. Только 35\% имеют кредит, причем в 81\% случаях - ипотечный, абсолютно все расплачиваются с ним безналичным способом. Наличие кредита не обязательно говорит о том, что человек обладает низким финансовым интеллектом, он просто может разумно распоряжаться своими ограниченными средствами, например, вкладывая в ценные бумаги или реализовывая какой-либо проект, при этом пока не имея собственной недвижимости.

На вопрос о наличии банковских карт, 94\% респондентов отметили, что пользуются ими, 80\% - дебитовой, 20\% - кредитной, 67\% имеют зарплатную карту, 3\% - корпоративную. Здесь важное замечание следует сделать по поводу кредитных карт, которые часто вызывают «финансовую ловушку», так как психологически обладатель такой карты понимает, что он может использовать в любое время деньги, они всегда есть на карте, поэтому тратит, не думая. Но если человек обладает высоким уровнем финансовой компетентности, то ему это не грозит.

Большее значение в вопросе о том, как человек оценивает свой уровень финансовой компетентности, получила оценка «4», на втором месте «3». Важная тенденция, которая выявилась при ответе на этот вопрос, показала, что мужчины выше оценивают свой уровень, чем женщины, независимо от финансового положения и имеющегося статуса.

Puc. 2. «Структура ответов на вопрос: Полагаетесь ли вы на мнение других людей в вопросе использования денежных средств?»

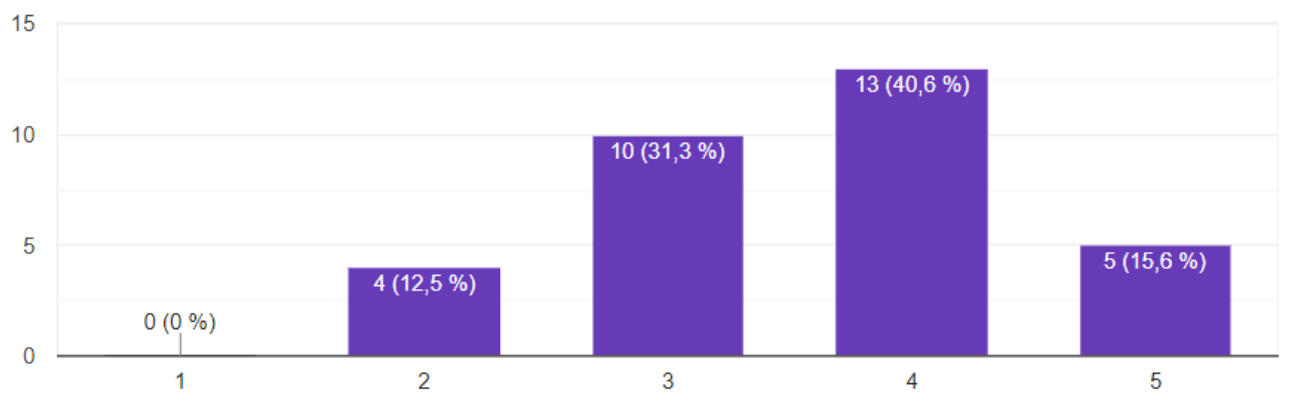

Puc. 3. «Уровень финансовой компетентности» 
Таким образом, данное исследование показало, что все люди, так или иначе занимающие руководящие должности в разных сферах, добиваются этого в том числе с помощью такого важного вида интеллекта, как финансовый, который позволяет быть компетентным в вопросе использования собственных активов и активов компании. В связи с этим следует понимать, как менеджерам и людям, которые хотят ими стать, развивать свой FQ. Для этого, в первую очередь, надо постоянно анализировать свои финансы и уметь планировать их использование. Также нужно исследовать пути новых вложений денежных средств, чтобы их приумножить, учиться сберегать, при этом не ограничивая себя ни в чем, общаться с людьми, которые добились высокого результата в финансовой сфере и могут поделиться опытом увеличения капитала.

\section{Обсуждение}

Современный менеджмент не выделяет единый пример идеального руководителя. У каждого управленца есть свои индивидуальные качества, которыми он пользуется в осуществлении своей деятельности, но в то же время есть отдельные навыки, которыми должны обладать все успешные менеджеры.

C момента появления тестов IQ (коэффициент интеллекта) многие считали, что это один из главных показателей «правильного» менеджера. Понятие коэффициента интеллекта ввёл немецкий учёный Вильгельм Штерн в 1912 году. IQ впервые был использован в шкале интеллекта Стэнфорд - Бине в 1916 году [4]. Но сегодня данный коэффициент утратил ценность в связи с многочисленными тестами, результаты которых очень трудно сравнивать.

Работа над систематизацией интеллекта происходит до сих пор, причем различные теории противостоят друг другу. Интересное мнение высказывает Г.Гарднер, создатель теории множественного интеллекта, он отмечает: «... нет и не может быть единой системы классификации интеллектов; никогда исследователи не составят эталонную классификацию из трех, семи или трехсот видов». Он считает, что люди наделены различными видами интеллекта, где выделяет следующие: вербальный, музыкальный, логико-математический, пространственный, телесно - кинестетический, внутриличностный, межличностный [1]. Несомненно, этот перечень не является исчерпывающим и окон- чательным; автор работает над теорией и по сей день.

По мнению многих специалистов - как теоретиков, так и практиков, наиболее важными видами интеллекта для менеджеров, работающих в разных сферах экономики и управления сегодня, становятся практический, эмоциональный, финансовый, творческий и другие. Наиболее исследованный и известный сегодня является эмоциональный интеллект. Первопроходцами в исследовании эмоционального интеллекта являются Дж. Майер и П. Сэловей, которые дали также определение: «набор навыков, имеющих отношение к точной оценке своих и чужих эмоций, а также выражению своих, использование эмоций, эффективному регулированию своих и чужих эмоций» [9]. Но наиболее популярной и признанной стала модель Д. Гоулмана, который выделил пять ключевых элементов: самосознание, саморегулирование, мотивация, умение сочувствовать, навыки общения (социальная чуткость). Эмоциональный интеллект или $\mathrm{EQ}-$ это способность понимать и управлять своими эмоциями и эмоциями окружающих вас людей. Люди с высоким уровнем эмоционального интеллекта знают, что они чувствуют, что означают их эмоции и как эти эмоции могут влиять на других людей. Для лидеров эмоциональный интеллект необходим для успеха.

В последнее время в связи с глобальными экономическими и финансовыми изменениями в мире специалисты в рамках общей модели интеллекта выделяют особый вид - финансовый интеллект (FQ). Идея финансового интеллекта относительно нова в научной литературе; недостаточно эмпирических и теоретических исследований проводится по данной теме, нет надежного определения $\mathrm{FQ}$, нет эмпирической меры для измерения FQ. Именно поэтому авторы статьи поставили целью исследовать наличие данного вида интеллекта у определенных людей и возможности развивать его для менеджеров.

B качестве примера определений FQ можно выделить следующие:

1) Англоязычная Википедия: Финансовый интеллект - это тип бизнес - аналитики, состоящий из знаний и навыков, полученных в результате понимания принципов финансов и бухгалтерского учета в деловом мире, а также понимания того, как используются деньги [5].

2) Р.Кийосаки «Финансовый интеллект это часть нашего общего интеллекта, которую 
мы используем для решения финансовых проблем, а финансовый IQ представляет собой меру его оценки»

В последней книге из популярной серии «Богатый папа, бедный папа» Кийосаки излагает свои 5 ключевых аспектов финансового интеллекта [6]:

1) Умение делать деньги (финансовый интеллект № 1). Оценка того, что можно сделать, чтобы увеличить свои финансовые активы при существующем положении и как рационально планировать свое финансовое будущее;

2) Умение сберегать деньги (финансовый IQ № 2). Тот, у кого финансовый интеллект меньше, тот платит больше налогов.

3) Умение составлять бюджет (Финансовый IQ № 3). Как правильно распоряжаться своими средствами, как рациональнее их использовать.

4) Умение использовать эффект рычага (Финансовый IQ № 4). Важно понимать, куда инвестировать свои средства, чтобы заработать максимум.

5) Умение повышать финансовую информированность (финансовый IQ № 5). Как увеличить свое богатство благодаря собственным финансовым знаниям, не полагаясь на других людей.

Однако авторы считают, что финансовый интеллект необходим не только отдельным менеджерам, а всем членам управленческой команды для улучшения качества при-нимаемых финансовых решений. Корпоративный финансовый интеллект - это не просто сумма FQ членов команды, здесь отражается синергетический эффект. Это также отно-сится и к эмоциональному интеллекту (EQ). Развивать EQ и FQ необходимо параллельно. Для конкретного понимания содержания различных аспектов FQ авторы провели расшифровку и составили соотношение вдиов эмоционального интеллекта (по Гоулману) и финансового интеллекта (по Кийосаки).

Авторы соглашаются с Р. Кийосаки в том, что развить финансовый интеллект нужно и можно абсолютно всем для того, чтобы быть успешным человеком, который умеет управлять деньгами. Для менеджера, работающего в сфере бизнеса, этот навык особенно важен, так как ему нужно реализовывать не только свои средства, но и средства компании. Ему обязательно помнить о том, что пассивные деньги никогда не станут источником богатства,- когда деньги не работают, они обесцениваются. Особую роль играет развитие нашего подсознания и кругозора - если человек будет довольствоваться тем, что есть, жить «по средствам», то добиться больших успехов вряд ли получится как у него самого, так и у компании, где он работает, поэтому менеджер должен постоянно анализировать финансовые данные, читать книги, работать в команде, чтобы повысить свой финансовый интеллект в том числе для того, чтобы суметь замотивировать своих сотрудников на будущие финансовые успехи и продвижение компании.

\section{Заключение}

В связи с наиболее сложными экономическими условиями в настоящее время человек стал развивать разнообразные виды интеллекта, чтобы суметь устоять в нестабильности и непредсказуемости. На наш взгляд, финансовый и эмоциональный интеллекты являются смежными, входят в состав друг друга, но не идентичны. Как и всякие другие виды интеллекта, финансовый интеллект также можно развивать. Наиболее подробно методику развития FQ представил Кийосаки, который отмечал, что воспитывать финансовый IQ можно с помощью различных институтов: школы, церкви, военной службы, сетевого маркетинга, бизнеса, семинаров, наставничества, клубов, веб-сайтов.

Результаты нашего опроса показали, что финансовой грамотностью обладает 65\% респондентов (выражается в знании видов финансовых услуг, финансовых продуктов, навыков планирования бюджета, умения финансировать средства, сбережения их).

Цифровизация экономики, развитие финансовых технологий потребует дальнейшего развития финансовой компетентности. В России в настоящее время различные финансовые структуры - ПАО «Сбербанк», АО «Альфабанк» и другие консалтинговые компания. Различные асоциации предпринимателей предлагают программы бизнес-образования, которые могут быть использованы для развития финансового интеллекта. 
Таблица 1. Виды EQ для менеджеров (по Д. Гоулману) [2] и их соотношение с видами FQ (по Р.Кийосаки)

\begin{tabular}{|c|c|c|c|}
\hline & Определение EQ & Признаки EQ & $\mathrm{FQ}$ \\
\hline Самосознание F1 & $\begin{array}{l}\text { Способность распознавать } \\
\text { и понимать свое настрое- } \\
\text { ние, эмоции, побуждения, } \\
\text { а также признавать их воз- } \\
\text { действие на других людей, } \\
\text { способность понимать свои } \\
\text { ильные и слабые стороны, } \\
\text { ценности и мотивы }\end{array}$ & $\begin{array}{l}\text { - Уверенность в себе; } \\
\text { - реалистичная самоо- } \\
\text { ценка; } \\
\text { - умение посмеяться над } \\
\text { собой; } \\
\text { - умение выслушать кон- } \\
\text { структивную критику; }\end{array}$ & $\begin{array}{l}\text { Осознание того, что } \\
\text { бизнес - это не только } \\
\text { прибыль/успех, но и риск, } \\
\text { что бизнес/предприятие } \\
\text { развивается циклично, а } \\
\text { кризисы, спад - неоть- } \\
\text { емлемый этап развития, } \\
\text { то есть FQ1 - это умение } \\
\text { делать деньги и обладать } \\
\text { финансовой интуицией }\end{array}$ \\
\hline Самоконтроль F2 & $\begin{array}{l}\text { Способность контроли- } \\
\text { ровать или направлять } \\
\text { в плодотворное русло } \\
\text { разрушительные импульсы } \\
\text { и эмоции; склонность к } \\
\text { разумному рассуждению по } \\
\text { принцип: «сначала поду- } \\
\text { май, прежде чем что-либо } \\
\text { делать» }\end{array}$ & $\begin{array}{l}\text { - Надежность и честность; } \\
\text { - спокойное отношение } \\
\text { к неопределенности и пере- } \\
\text { менам; } \\
\text { - открытость всему ново- } \\
\text { му; }\end{array}$ & $\begin{array}{l}\text { FQ2 - Для того чтобы } \\
\text { «делать деньги», нужно } \\
\text { освоить профессию, а для } \\
\text { этого обладать навыками } \\
\text { контроля и умения направ- } \\
\text { лять в плодотворное русло } \\
\text { разрушительные эмоции } \\
\text { и импульсы, особенно в } \\
\text { кризисных условиях }\end{array}$ \\
\hline Мотивация F3 & $\begin{array}{l}\text { Увлеченность работой, } \\
\text { желание трудиться, не обу- } \\
\text { словленные исключительно } \\
\text { соображениями высокого } \\
\text { заработка или статуса.; же- } \\
\text { лание работать ради самого } \\
\text { процесса; стремление упор- } \\
\text { но и энергично добиваться } \\
\text { поставленных целей. }\end{array}$ & $\begin{array}{l}\text { - стремление к достиже- } \\
\text { ниям; } \\
\text { - оптимизм даже перед } \\
\text { лицом неудач; } \\
\text { - приверженность ценно- } \\
\text { стям организации; } \\
\text { - любовь к работе как та- } \\
\text { ковой, готовность к новым } \\
\text { испытаниям; } \\
\text { - стремление к совершен- } \\
\text { ствованию; }\end{array}$ & $\begin{array}{l}\text { FQ3 - умение составлять } \\
\text { бюджет. Другими сло- } \\
\text { вами,- это способность } \\
\text { откладывать удовольствие } \\
\text { (которое можно купить за } \\
\text { деньги), что соответствует } \\
\text { принипу: сначала поду- } \\
\text { май, прежде чем что-либо } \\
\text { сделать; } \\
\text { - умение разумно риско- } \\
\text { вать; } \\
\text { - умение создавать стра- } \\
\text { ховые запасы; } \\
\text { - стремление к финансо- } \\
\text { вой независимости }\end{array}$ \\
\hline Эмпатия F4 & $\begin{array}{l}\text { Способность понимать эмо- } \\
\text { циональное состояние дру- } \\
\text { гих людей; умение вести } \\
\text { себя с людьми в соответ- } \\
\text { ствии с их эмоциональны- } \\
\text { ми реакциями; способность } \\
\text { понимать эмоциональное } \\
\text { состояние других людей, } \\
\text { особенно при принятии } \\
\text { сложных решений }\end{array}$ & $\begin{array}{l}\text { - умение находить и удер- } \\
\text { живать высококвалифици- } \\
\text { рованных специалистов в } \\
\text { организации; } \\
\text { - способность давать } \\
\text { возможность развиваться } \\
\text { персоналу; } \\
\text { - уважительное и чуткое } \\
\text { отношение к особенностям } \\
\text { другой культуры; }\end{array}$ & $\begin{array}{l}\text { FQ4 - умение использо- } \\
\text { вать эффект рычага. Чтобы } \\
\text { использовать навыки и } \\
\text { таланты других людей ради } \\
\text { извлечения определенной } \\
\text { пользы, необходимо обла- } \\
\text { дать чувством эмпатии, а } \\
\text { также умением заводить } \\
\text { финансовых партнеров, } \\
\text { друзей и трезво оценивать } \\
\text { их способности }\end{array}$ \\
\hline $\begin{array}{l}\text { Социальные навыки } \\
\text { F5 }\end{array}$ & $\begin{array}{l}\text { Умение управлять чело- } \\
\text { веческими отношениями } \\
\text { и налаживать контакты; } \\
\text { способность к эффективно- } \\
\text { му осуществлению новых } \\
\text { видений }\end{array}$ & $\begin{array}{l}\text { - Способность к эффек- } \\
\text { тивному осуществлению } \\
\text { нововведений; } \\
\text { - умение убеждать; } \\
\text { - владение искусством } \\
\text { руководства коллективом, } \\
\text { навык его формирования; } \\
\text { - способность находить } \\
\text { точки соприкосновения до- } \\
\text { биваются взаимодействия; }\end{array}$ & $\begin{array}{l}\text { FQ5 - умение повышать } \\
\text { финансовую информиро- } \\
\text { ванность. Источниками } \\
\text { важной информации явля- } \\
\text { ются не все СМИ или курсы } \\
\text { по повышению квалифика- } \\
\text { ции, а люди. Поэтому уме- } \\
\text { ние налаживать контакты } \\
\text { и выстраивать коммуника- } \\
\text { ции, необходимо для полу- } \\
\text { чения финансовой прав- } \\
\text { дивой информации, для } \\
\text { привлечения финансовых } \\
\text { советников, для поддер- } \\
\text { жания финансовых связей } \\
\text { и способности оказывать } \\
\text { финансовую помещь своим } \\
\text { партнерам. }\end{array}$ \\
\hline
\end{tabular}




\section{Библиографический список}

1. Говард Гарднер. Структура разума: теория множественного интеллекта.- М.: ООО «И.Д. Вильямс», 2007.$512 \mathrm{c}$.

2. Д. Гоулман «Эмоциональный интеллект. Почему он может значить больше, чем IQ»// 1995 by Daniel Goleman. Introduction copyright 540 стр.

3. Лебедева Т.В.Формирование профессиональных компетенций в финансовой сфере: международный аспект, архитектура финансов: антикризисные финансовые стратегии в условиях глобальных перемен: сборник материалов VII международная научно - практическая конференция, 2016 г., стр. 449-453

4. Определение коэффициента интеллекта [https://ru.wikipedia.org/wiki/Коэффициент_интеллекта]

5. Определение финансового интеллекта [https://en.wikipedia.org/wiki/Financial_intelligence_(business)]

6. Роберт Т. Кийосаки и Шэрон Л. Лектер «ПОДНИМИТЕ СВОЙ ФИНАНСОВЫЙ IQ»// По изданию: INCREASE YOUR FINANCIAL IQ by Robert T. Kiyosaki., 2008 г.

7. «Тест Дж. Мэйера, П. Сэловея, Д. Карузо «Эмоциональный интеллект» (MSCEIT v. 2.0): Руководство»

8. Формирование компетенций в области финансовой культуры. НВ Митяева, ЕА Орехова, АД Бобкова - Вестник Саратовского государственного социально-экономического института, 2017, № 3 (67), стр. 138-140

9. Сергиенко, Ветрова: Тест Дж. Мэйера, П. Сэловея, Д. Карузо «Эмоциональный интеллект» (MSCEIT v. 2.0): Руководство// Издательство: Институт психологии РАН, 2010 г. 